\title{
Small trials focusing on surrogate end points may be uninformative : [Letter]
}

\section{Hemilä, Harri}

2007

Hemilä , H 2007 , ' Small trials focusing on surrogate end points may be uninformative :

[Letter] ' , European Journal of Applied Physiology , vol. 99 , no. 6 , pp. 707-708 . https://doi.org/10.1007/s00421-006

http://hdl.handle.net/10138/228092

https://doi.org/10.1007/s00421-006-0387-2

acceptedVersion

Downloaded from Helda, University of Helsinki institutional repository.

This is an electronic reprint of the original article.

This reprint may differ from the original in pagination and typographic detail.

Please cite the original version. 


\title{
Small trials focusing on surrogate end points may be uninformative [Letter to the Editor]
}

\section{Hemilä H}

European Journal of Applied Physiology 2007;99:707-708

Published version: http://dx.doi.org/10.1007/s00421-006-0387-2

\section{Pre-print version of the manuscript}

\author{
Harri Hemilä \\ Department of Public Health, POB 41 \\ University of Helsinki, \\ FIN-00014 \\ Finland \\ harri.hemila@helsinki.fi \\ http://www.ltdk.helsinki.fi/users/hemila
}

Experts of controlled clinical trials argue that conclusions about the effects of medical interventions should be based on clinically relevant outcomes and not on surrogates such as laboratory measurements. There are several examples in which the effect on a clinically relevant outcome considerably diverged from the effect on a surrogate end point (Fleming and DeMets 1996; Rothwell 2005). In this respect, the recent paper by Davison and Gleeson (2006) is somewhat problematic.

Davison and Gleeson motivated their study by noting that heavy exertion or long-duration exercise may increase the incidence of upper respiratory tract infection (URI) and by citing two trials in which vitamin $\mathrm{C}$ reduced the risk of URI associated with marathon runs. Evidence that vitamin C supplementation may be beneficial for people who are under heavy physical stress is, however, substantially stronger than Davison and Gleeson present.

A recent Cochrane meta-analysis focusing on vitamin $\mathrm{C}$ and the common cold found six placebocontrolled trials with participants under heavy acute physical stress (combined $\mathrm{N}=642$ ). In this group of trials vitamin C reduced common cold risk by 50\% (95\% CI: $-34 \%$ to $-62 \%$ ) (Douglas and Hemilä 2005; Hemilä 2006). Four of the trials, including those cited by Davison and Gleeson, were carried out with marathon runners, the fifth with Canadian soldiers in a winter exercise (Sabiston and Radomski 1974), and the sixth with schoolchildren in a skiing camp in the Swiss Alps (Ritzel 1961). Moreover, heavy physical stress is a prominent feature of military recruits who concomitantly have elevated risk of pneumonia. Therefore the large $(\mathrm{N}=674)$ randomized double-blind placebo-controlled trial with US Marine recruits is particularly interesting: vitamin $\mathrm{C}$ reduced the incidence of pneumonia by $85 \%(\mathrm{P}[2-\mathrm{t}]$ = 0.044; Pitt and Costrini 1979; Hemilä 2004, 2006).

In their trial, Davison and Gleeson compared vitamin $\mathrm{C}$ and control periods in the same participants exercising with a cycle ergometer and measured changes in the immune system. Such a study focusing on surrogates of infection susceptibility does not yield any information about whether vitamin $\mathrm{C}$ supplementation actually affects the risk of URI or more severe respiratory infections - the clinically relevant outcomes - in physically stressed people.

On the other hand, the statistically very strong effect of vitamin C on URI risk in physically stressed people (Douglas and Hemilä 2005) calls for immunological explanations. However, if the 
purpose of a study is to provide an immunological explanation for the vitamin $\mathrm{C}$ effect on URI risk, the study should concurrently validate that vitamin C indeed has effect on URI incidence at the particular experimental conditions, because the effect has been found only in extreme physical stress. In ordinary people vitamin $C$ has no effect on URI risk (Douglas and Hemilä 2005). The data for URI episodes were not collected by Davison and Gleeson and therefore we do not know whether vitamin C reduced URI incidence in their physical stress model. If the effect of vitamin C on URI incidence is not confirmed at the particular study conditions, we do not know whether the immunological findings have any relation to the biological mechanisms explaining the effect of vitamin C on URI risk, the clinically relevant outcome.

A further major problem of the Davison and Gleeson trial is the very small size $(\mathrm{N}=9)$. In the Pitt and Costrini trial, the number-needed-to-treat (NNT) to prevent one case of pneumonia with vitamin $\mathrm{C}$ was 57. The NNT to prevent one case of the common cold with vitamin C was 7 in the Sabiston and Radomski trial, and 10 in the Ritzel trial. Concluding from such NNT values, it is evident that, as a minimum, several dozens of participants are needed at appropriate experimental conditions for a study to analyze whether immune system changes caused by vitamin $C$ supplementation have any correlations with the clinical effects.

\section{References}

Davison G, Gleeson M (2006) The effect of 2 weeks vitamin C supplementation on immunoendocrine responses to $2.5 \mathrm{~h}$ cycling exercise in man. Eur J Appl Physiol 97:454-461 http://dx.doi.org/10.1007/s00421-006-0196-7

Douglas RM, Hemilä H (2005) Vitamin C for preventing and treating the common cold. PLoS Med 2:e168 http://dx.doi.org/10.1371/journal.pmed.0020168

Fleming TR, DeMets DL (1996) Surrogate end points in clinical trials: are we being misled? Ann Intern Med 125:605-613 http://www.annals.org/cgi/content/abstract/125/7/605

Hemilä H (2004) Vitamin C supplementation and respiratory infections: a systematic review. Mil Med 169:920-925 http://www.ingentaconnect.com/content/amsus/zmm/2004/00000169/00000011/art00026 http://www.findarticles.com/p/articles/mi_qa3912/is_200411/ai_n9469932

Hemilä H (2006) Do vitamins $C$ and $E$ affect respiratory infections? [PhD Thesis] University of Helsinki, Helsinki, Finland, pp 48-51 Available at: http://ethesis.helsinki.fi/julkaisut/laa/kansa/vk/hemila/

Pitt HA, Costrini AM (1979) Vitamin C prophylaxis in marine recruits. JAMA 241:908-911 http://dx.doi.org/10.1001/jama.241.9.908

Ritzel G (1961) Critical analysis of the role of vitamin C in the treatment of the common cold [in German]. Helv Med Acta 28:63-68 English translation at: http://www.ltdk.helsinki.fi/users/hemila/T3.pdf

Rothwell PM (2005) External validity of randomised controlled trials: "To whom do the results of this trial apply?" Lancet 365:82-93 http://dx.doi.org/10.1016/S0140-6736(04)17670-8

Sabiston BH, Radomski MW (1974) Health Problems and Vitamin C in Canadian Northern Military Operations. DCIEM Report no. 74-R-1012. Defence and Civil Institute of Environmental Medicine, Downsview, Ontario, Canada, $10 \mathrm{pp}$ http://www.ltdk.helsinki.fi/users/hemila/CC/Sabiston_1974_ch.pdf 